\title{
CIBEC
}

\section{Teses e dissertações recebidas}

São divulgadas as referências bibliográficas das teses recebidas pelo Cibec no período anterior ao lançamento do número subseqüente da RBEP. Todo o acervo das teses indexadas poderá ser acessado diretamente no Cibec ou via Internet.

AGUIAR, Raymunda Viana. Desenvolvimento, implementação e avaliação de ambiente virtual de aprendizagem em um curso profissionalizante de enfermagem. 2005. 132 f. Tese (Doutorado em Enfermagem) - Universidade de São Paulo, Ribeirão Preto, 2005.

Orientadora: Silvia Helena de Bortoli Cassiani

Os objetivos deste estudo foram: desenvolver, implementar e avaliar o Ambiente Virtual de Aprendizagem (Avap) na temática "Administração de Medicamentos", a alunos do curso profissionalizante em enfermagem de uma escola técnica de universidade pública na cidade de Curitiba, PR, e avaliar a aprendizagem destes alunos através de média obtida após o uso do programa.

ALterthum, Camila Carvalhal. $O$ encontro com crianças filhas de catadores de papel: sinalizações para uma creche e uma pesquisa com a "nossa cara". 2005. 137 f. Dissertação (Mestrado em Educação) - Faculdade de Educação, Universidade Federal de Minas Gerais, Belo Horizonte, 2005.

Orientadora: Maria Amélia G. de Castro Giovanetti

Pesquisa junto a crianças menores de seis anos, filhas de catadores de papel, que teve dois objetivos: o primeiro, buscar na interlocução com as crianças as fundamentações para o trabalho pedagógico da creche que viria a atendêlos; o segundo, revelado na busca do primeiro, refletir a respeito das sinalizações que estas crianças ofereciam para a prática da pesquisa no campo da infância.

BONATTO, Jaklane de Souza Almeida. A construção histórica da profissionalidade docente no Espírito Santo (1908-1930): um estudo sobre as reformas educacionais de Gomes Cardim e Attilio Vivacqua. 2005. 104 f. Dissertação (Mestrado em Educação) - Programa de Pós-Graduação em Educação, Universidade Federal do Espírito Santo, Vitória, 2005.

Orientadora: Regina Helena Silva Simões

Estuda a construção histórica da profissionalidade docente no Espírito Santo a partir de duas reformas educacionais do início do século 20: uma no governo de Jerônimo Monteiro - 1908 a 1912, conduzida por Carlos Alberto Gomes Cardim; outra no governo de Aristeu Borges de Aguiar - 1928 a 1930, conduzida por Attilio Vivacqua.

CARVAlHO, Angela Maria Grossi de. Alfabetização digital: um estudo sobre a apropriação dos instrumentos de e-gov na 
educação. 2005. 118 f. Dissertação (Mestrado em Educação) - Programa de Pós-Graduação em Educação, Universidade Metodista de Piracicaba, Piracicaba, 2005.

\section{Orientador: Hugo Assmann}

Trata do tema alfabetização digital e sua aplicação no campo da educação. Para verificar se as ações propostas pelo governo eletrônico (e-gov) estão realmente contribuindo para a disseminação da alfabetização digital foi analisado o programa Gesac - Governo Eletrônico de Serviço de Atendimento ao Cidadão.

CARVALHO, Elma Júlia Gonçalves de. Autonomia da gestão escolar: democratização e privatização, duas faces de uma mesma moeda. 2005. 235 f. Tese (Doutorado em Educação) - Programa de Pós-Graduação em Educação, Universidade Metodista de Piracicaba, Piracicaba, 2005.

\section{Orientador: Valdemar Sguissardi}

Os temas descentralização educativa e autonomia da gestão escolar vêm ganhando campo nos debates políticos e pedagógicos. No quadro político de redemocratização do País, a maior participação da comunidade na vida da escola, através de ações colegiadas, tornouse bandeira de luta cujo objetivo era a maior democratização das relações escolares e do processo decisório em relação aos órgãos superiores da administração.

CHAVES, Vera Lúcia Jacob. As feições da privatização do público na educação superior brasileira: o caso da UFPA. 2005. 2 v. Tese (Doutorado em Educação) Faculdade de Educação, Universidade Federal de Minas Gerais, Belo Horizonte, 2005.

Orientadora: Maria do Carmo Lacerda Peixoto

Analisar os desdobramentos/tipologias que o privado assume no interior das universidades públicas a partir da reforma da educação superior implementada no período de 1995 a 2002, tendo como locus de investigação a Universidade Federal do Pará. A intenção foi analisar como o processo de privatização vai sendo naturalizado no interior da universidade e promovendo alterações substantivas na organização da instituição.

GUIMARO, Maria Luiza Oliveira. A individuação na linha de fogo: videogames de guerra e dessubjetivação. 2005. $123 \mathrm{f}$. Dissertação (Mestrado em Educação) Programa de Pós-Graduação em Educação, Universidade Metodista de Piracicaba, Piracicaba, 2005.

Orientador: Luiz Antônio Calmon Nabuco Lastória

Aborda os motivos que fazem com que os jovens se desinteressem pelos bancos escolares e os troquem pelos bancos das Lans Houses. Investiga elementos da cultura atual - em especial o uso compulsivo dos videogames de guerra que parecem estar promovendo mudanças na constituição identitária e subjetiva dos jovens, incitando-os a comportamentos compulsivos e viciantes. Os jogos virtuais de guerra, os RPGs e a crescente mania das Lan Houses, combinados, induzem os usuários a uma verdadeira compulsão à repetição - e parece indicar, também, uma busca infinita por figuras de heróis -, promovendo uma verdadeira descarga pulsional mortífera de quando na utilização desses jogos virtuais.

LUZ, Iza Rodrigues da. Agressividade na primeira infância: um estudo a partir das relações estabelecidas pelas crianças no ambiente familiar e na creche. 2005. $197 \mathrm{f}$. Tese (Doutorado em Educação) - Faculdade de Educação, Universidade Federal de Minas Gerais, Belo Horizonte, 2005.

Orientador: Luiz Alberto Oliveira Gonçalves

Investiga a agressividade na primeira infância, a partir das relações estabelecidas pelas crianças no ambiente familiar e na instituição de educação infantil. 
OKIMURA, Tiemi. Processo de aprendizagem de idosos sobre os benefícios da atividade física. 2005. 117 f. Dissertação (Mestrado em Educação Física) - Universidade de São Paulo, São Paulo, 2005.

\section{Orientadora: Silene Sumire Okuma}

Analisa o processo de aprendizagem de idosos sobre os benefícios da atividade física. Verificou-se também elementos que predispuseram a aprendizagem, como: interesse em aprender, associação do aprendido com atividades cotidianas e utilização de conhecimentos prévios. Os fatores que dificultaram a aprendizagem ou a sua expressão foram: conceitos prévios inadequados, diminuição da memória, baixa escolaridade e falta de domínio da linguagem oral. Pode-se concluir que os benefícios da atividade física foram além dos efeitos fisiológicos e que a elaboração pessoal do conhecimento se deu com base em aspectos da experiência de vida de cada idoso.

OLIVEIRA, Raquel Aparecida de. A universidade como espaço promotor de qualidade de vida: vivências e expressões dos alunos de enfermagem. 2005. $233 \mathrm{f}$. Tese (Doutorado em Enfermagem) Universidade de São Paulo, São Paulo, 2005.

Orientadora: Maria Helena Trench Ciampone

Identifica as percepções que o aluno de graduação em enfermagem tem em relação a sua qualidade de vida atual e a futura qualidade de vida no trabalho; compreende e analisa as principais demandas por eles evidenciadas no resgate das situações vividas e as estratégias de enfretamento utilizadas que impactam na melhoria da sua qualidade de vida.

PAVANELLI, Fabiana Furlanetto de Oliveira. Urdidura e trama: tecendo a significação da formação e da docência com um grupo de professoras. 2005. 144 f. Dissertação (Mestrado em Educação) -
Programa de Pós-Graduação em Educação, Universidade Metodista de Piracicaba, Piracicaba, 2005.

Orientadora: Roseli Aparecida Cação Fontana

Compreende os processos formativos que se instauram nas relações entre professoras e os significados e sentidos da docência que neles são elaborados; focaliza as interlocuções produzidas nos encontros de um grupo de estudos constituído por cinco professoras. A docência e a formação são entendidas como produções históricas que se singularizam como experiência elaborada e compartilhada pela linguagem.

PORTO, Joyce Calixto. Relação entre infância e televisão: o olhar da família e da escola. 2005. 95 f. Dissertação (Mestrado em Psicologia) - Centro de Ciências da Vida, Pontifícia Universidade Católica de Campinas, Campinas, 2005.

Orientador: Fernando L. Gonzalez Rey

Compreende a relação entre infância e televisão, na visão da escola e da família, e os sentidos subjetivos que se configuram nesta interação. Pelo fato de a televisão fazer parte do cotidiano das crianças, é importante que se investigue como esses conteúdos são recebidos por elas.

RUIZ, Valdete Maria. Aprendizagem em universitários: variáveis motivacionais. 2005. 172 f. Tese (Doutorado em Psicologia) - Centro de Ciências da Vida, Pontifícia Universidade Católica de Campinas, Campinas, 2005.

Orientadora: Geraldina Porto Witter

Faz uma análise de variáveis motivacionais que influenciam a aprendizagem de universitários. Verifica a ocorrência das variáveis: orientação para a meta intrínseca, orientação para a meta extrínseca, valor da tarefa, crenças sobre o controle da aprendizagem, auto-eficácia para aprendizagem e desempenho e ansiedade ante as provas, analisando a ocorrência de correlação entre as escalas motivacionais que avaliaram essas variáveis em ingressantes e concluintes. 
SARAIVA, Ana Cláudia Lopes Chequer. Representações sociais da aprendizagem docente de professores universitários em suas trajetórias de formação. 2005. $285 \mathrm{f}$. Tese (Doutorado em Educação) Faculdade de Educação, Universidade Federal de Minas Gerais, Belo Horizonte, 2005.

Orientadora: Regina Helena de Freitas Campos

Identifica os espaços socioeducativos, experiências, processos e interlocutores que se integraram às suas trajetórias pessoais no âmbito da aprendizagem docente, além da análise das relações entre as representações dos docentes e os estatutos epistemológicos disciplinares que lhes fundamentam os campos de formação e atuação profissional.

SILVA, Rosa Maria Alves da. E o caminho se fez assim... análise de experiência de formação docente inicial e continuada. 2005. 196 f. Tese (Doutorado em Educação) - Programa de Pós-Graduação em Educação, Universidade Metodista de Piracicaba, Piracicaba, 2005.

Orientadora: Roseli Aparecida Cação Fontana
Propôs aprender como a docência e a formação foram sendo significadas e vividas na dinâmica interativa produzida entre sujeitos envolvidos numa situação de estágio. A autora da pesquisa, como professora de prática de ensino e supervisora de estágios durante três anos, de 2001 a 2003, coordenou um projeto pedagógico, junto a estagiários do curso de pedagogia e direção, coordenação e professores de uma escola municipal de educação fundamental. Articulada a esse trabalho pedagógico, a pesquisa de campo com o objetivo acima citado foi desenvolvida através da documentação e da análise das relações interpessoais que foram sendo produzidas nas relações sociais vivenciadas.

SOUZA, Sandra Medina de. O perfil profissional do pedagogo e sua atuação na educação básica: uma construção. 2005. 192 f. Dissertação (Mestrado em Educação) - Faculdade de Educação, Universidade Federal de Minas Gerais, Belo Horizonte, 2005.

Orientadora: Ângela Imaculada Loureiro de Freitas Dalben

Investiga o perfil profissional do pedagogo e as suas competências, que vêm sendo exigidas e construídas na prática escolar. 